\title{
GEOSTATISTICAL ANALYSIS OF TOMATO FRUIT ROT AND DIVERSITY OF ASSOCIATED FUNGAL SPECIES
}

\author{
A. Hussain*1, S. W. Khan², S. Ali ${ }^{1}$, F. Faiz ${ }^{1}$, M. Hussain ${ }^{1}$, A. Ali ${ }^{1}$, Shams Ur Rahman³ and S. Qasim ${ }^{1}$ \\ ${ }^{1}$ Department of Agriculture and Food Technology Karakoram International University Gilgit \\ ${ }^{2}$ Department of Biological Sciences Karakoram International University Gilgit \\ ${ }^{3}$ Department of Mathematical Sciences Karakoram International University Gilgit \\ *Corresponding author mail: azhar.hussain@kiu.edu.pk
}

\begin{abstract}
Tomato fruit rot caused by fungi is the most common postharvest problem. The fungi are responsible for spoilage of produce between harvest and consumption. This study analyzed the distribution of tomato fruit rot using descriptive as well as geostatistical techniques and diversity of associated fungal species. Descriptive statistics indicated that the rot incidence and severity ranged from $10.22-44.17 \%$ and $0.7-7.10 \mathrm{~mm}$. Geostatistical techniques were used to predict the spatial dependency class. Results revealed that rot incidence data had a nugget/ sill ratio of 0.487 inferring moderate spatial dependence, whereas severity inferring weak spatial dependence with nugget/ sill ratio of 0.221 . Furthermore, geostatistical analysis was also applied to examine spatial variability within-field using semivariogram and kriged maps. The maps of current study showed spatial distribution of rot incidence and severity in the study area. These digital maps will be helpful to develop pre- and post-harvest management strategies against tomato fruit rot. A total of nine fungal species were isolated from infected tomato fruit namely; Geotrichum candidum, Alternaria alternata, Aspergillus flavus, Aspergillus niger, Bipolaris, Fusarium oxysporum, Rhizopus stolonifer, Culvularia lunata and Penicillum digitatum. Aspergillus flavus was dominating species (17.02\%) followed by Fusarium oxysporum (14.89\%) and Alternaria alternata $(12.76 \%)$, while Culvularia lunata has the least occurrence (6.38\%). This study provides information about post-harvest rotting fungi of tomato to the growers, extension workers and researchers in the district Gilgit.
\end{abstract}

Key words: Tomato rot, distribution, GIS, geostatistics, associated fungi, Gilgit-Baltistan

https://doi.org/10.36899/JAPS.2021.4.0297

Published online December 15, 2020

\section{INTRODUCTION}

Postharvest diseases of fruits and vegetables may occur at the time of harvesting to consumption that make food commodity toxic and reduce aesthetic value due to alterations in appearance, texture, taste or smell (Akinmusire, 2011). Tomato (Solanum lycopersicum L.) which belongs to the family Solanaceae is an important vegetable crop grown throughout the World. It is considered as highly nutritious due to its high contents of vitamin $\mathrm{A}$ and $\mathrm{C}$ as well as lycopene; a natural antioxidant. It has niacin $0.712 \mathrm{mg}$, calcium $31 \mathrm{mg}$ and water $94.28 \mathrm{~g}$ per $100 \mathrm{~g}$ weight (Wamache, 2005; Ewulo et al., 2008). It is the $2^{\text {nd }}$ most consumed vegetable next to potato and ranked first among the processing crops. It is the most popular and key vegetable grown in the entire world and significantly contributes to the world's vegetable economy (FAOSTAT, 2019; Quinet et al., 2019; FAO, 2005). In the developing countries tomato fruits are displayed in baskets at the open markets, thereby exposing them to opportunistic microbial infections especially mycotoxins producing organisms. Microbial contamination of fruits and vegetables may occur during harvesting, storage, packaging and transportation (Baiyewu et al., 2007; Barth et al., 2009). The poor postharvest handling practices in the developing countries amounting to approximate losses $>30 \%$ of fresh fruits and vegetables (Kader, 2005; Agrios, 2005). Like other crops; a huge amount of tomato crops is lost after harvest. The main factors of post-harvest losses are; careless harvesting, dumping of produce, improper storage, bulk packaging and transportation to the distant markets. All these activities increase moisture condensation which supports pathogen infestation and decay of produce.

Due to perishable nature of tomato fruits; postharvest decay remains a major challenge to the grower (Mujib et al., 2007). There are numerous microorganisms including fungi, bacteria, viruses and nematodes that cause different diseases of tomatoes. Amongst; fungi are mainly responsible for causing serious threats to the quality of tomato fruit. Furthermore, high contents of moisture make tomato fruit more prone to fungal contamination (Efiuvwevwere, 2000; Kalyoncu et al., 2005; Wani, 2011).

Several fungi caused rots reported all over the world having varying intensities on tomato (Iqbal et al., 2003; Patel et al., 2005; Ali et al., 2005). Adequate information about microbial contamination and handling practices could lessen postharvest wastage of fruits. Tomato fruit having high water contents $(80 \%)$, rich nutrient, sugar as well as low $\mathrm{pH}$, serves as an excellent 
environment for microbial contamination (Singh and Sharma, 2007). Farmer and tomato seller of GilgitBaltistan are faced with serious losses due to attack of microbes especially by rot pathogens. The losses may start from field and continue to sale at the market. Knowledge of microbial contamination of tomato fruits is necessary to developed postharvest management strategies with specific treatment before reaching to consumer to avoid adverse human health and financial impacts.

Spatial distribution of plant disease by using GIS has identified the areas where infestation is high and it helps in devising effective management strategies (Richard et al., 2005). In this study; the spatial distribution of tomato rot and associated fungus was assessed using descriptive and geostatistical software. The study also used semivariogram analysis to narrate the spatial pattern and generate tomato rot probability maps by using kriging techniques. This study also addresses abundance and diversity index of associated fungal species.

\section{MATERIALS AND METHODS}

Spatial distribution of tomato rot: To assess spatial distribution of tomato rot (incidence and severity); tomato fruits showing rotting symptom were collected from different fields, shops/ markets in the selected valleys of districts Gilgit (Fig. 1). A total of fifty tomato fruits were randomly collected from each point and calculated incidence and severity by using following formula:

\section{N.T.R.T}

T.R.I \% = ----------X 100

T.N.T.I

T.R.I $\%=$ Tomato rot incidence percentage; N.T.R.I $=$ Number of tomato rot infected; T.N.T.I $=$ Total number of tomatoes inspected

Tomato rot severity was determined according to scale ( $\leq 3 \mathrm{~mm} ; 3-5 \mathrm{~mm}$ and $\geq 6 \mathrm{~mm}$ rot length). The rot severity index percentage was calculated by using following formula;

$$
\text { D.S.I }=\sum \text { A.R/T.N.R (M.D) } x 100
$$

(D.S.I $=$ Disease severity index; $\sum$ A. $R=$ Sum of all disease rating; T.N.R = Total number of rating; $M . D=$ Maximum disease grade.

Geostatistical analysis and Spatial Variability Mapping of tomato Rot: Geostatistical analysis was used to describe the spatial distribution of tomato rot in term of incidence and severity. ArcGIS 10.1 and ArcGIS Geostatistical Analyst were used for mapping of disease. Kriging technique was used to interpolate the values of unsampled locations as described by Caers, 2003. The following formula was used for kriging;

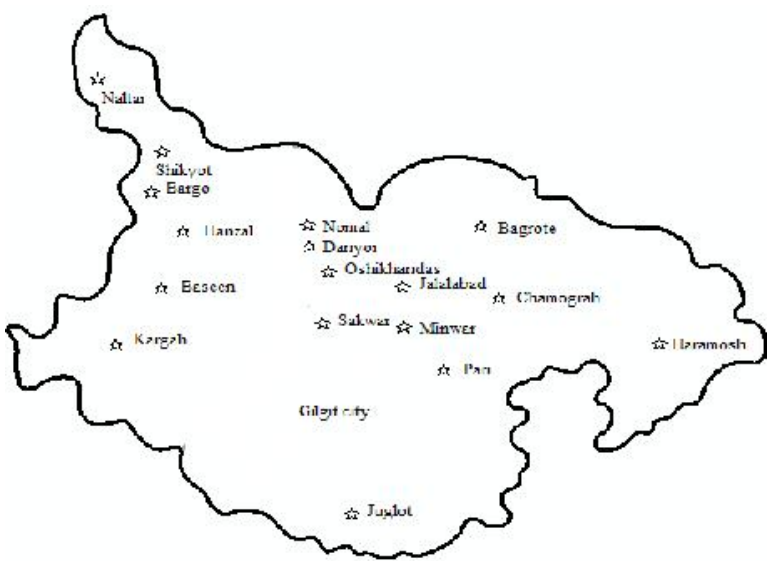

Figure1. Map of study area District Gilgit.

$$
\hat{Z}(s o)=\sum_{i=1}^{N} \lambda_{i} Z(S i)
$$

Where: $\boldsymbol{Z}\left(\boldsymbol{s}_{i}\right)=$ the measured value at the $i$ th location; $\boldsymbol{\lambda}_{\boldsymbol{i}}=$ an unknown weight for the measured value at the $i$ th location; $\boldsymbol{s}_{\boldsymbol{0}}=$ the prediction location; $\boldsymbol{N}=$ the number of measured values.

Semivariogram can be fitted with spherical model presented by Olea 2003; Webster and Oliver, 2007. Spherical $=\mathrm{y}(h)=\left\{\mathrm{C}_{0}+\mathrm{C}\left(3 \mathrm{~h} / 2 \mathrm{ac}-1 / 2(\mathrm{~h} / \mathrm{a})^{3}\right.\right.$

$0 \leq \mathrm{h}<\mathrm{a}$

$\mathrm{h} \geq \mathrm{a}$

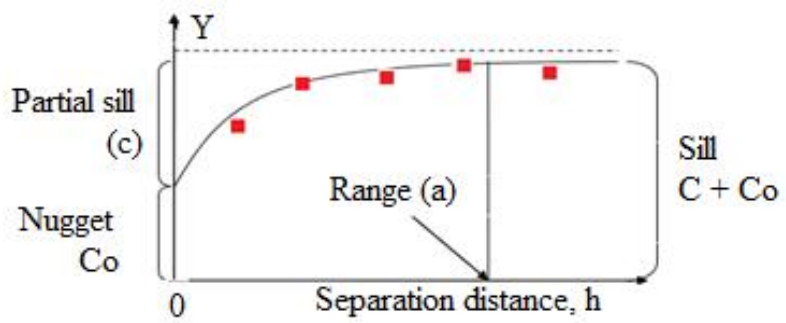

Spatial dependence (SDP \%) was calculated as described by Biondi et al. (1994), is given by the expression;

$\mathrm{C}_{1}$

SDP Spherical \% = ----------- x 100

$\mathrm{C}_{0}+\mathrm{C}_{1}$

For the spherical semivariogram: SDP Spherical (\%) was taken as; $\leq 25 \%$ weak spatial dependence; $25 \%<$ SPD $(\%) \leq 75 \%$ moderate spatial dependence and $\geq 75 \%$ strong spatial dependence. Spatial analyst function of Arc GIS software was used to prepare maps as described by Azhar et al., (2016).

Collection and Isolation of fungal Species: Infected tomato fruits were collected during survey and brought to laboratory for isolation of associated fungal species. Before isolation, all the fruits samples were washed twice in distilled water and then surface sterilized by immersion for $3 \mathrm{~min}$ in 3\% sodium hypochlorite and further washed three times in sterilized distilled water for $2 \mathrm{~min}$ each time. 
After sterilization, infected fruits samples were cut into small pieces and placed into potato dextrose agar containing Petri-plates with $50 \mu \mathrm{g} / \mathrm{mL}$ of streptomycin. These Petri plates were incubated at $27 \pm 2^{\circ} \mathrm{C}$ with normal $\mathrm{dl} / \mathrm{d}$ periods. The plates were examined daily for up to two weeks for the development of fungal colonies growing out from the infected fruits segments. Fungal species were identification according to the protocol (Hyde et al., 2000). The relative percentage occurrence (RPO \%) and diversity index (Simpson and Shannon) were calculated based on the standard methods (Zar, 2004).

N.I.F
RPO \% = ---------------- x 100

T.N.F

RPO \%: Relative percentage occurrence; N.I.F: Number of individual fungal species; T.N.F: total number of fungal species

Diversity Index: Simpson and Shannon-wiener diversity index was calculated using the formula

$$
\begin{gathered}
\mathrm{D}=1-\mathrm{n}(\mathrm{n}-1) \\
\mathrm{NH}(\mathrm{N}-1) \\
\mathrm{sHs}=\sum(\mathrm{Pi})(\mathrm{InPi}), \mathrm{i}=1
\end{gathered}
$$

\section{RESULTS}

The current study was undertaken to assess the incidence and severity of fungal infestation in tomato crop and provide a baseline data for development of crop management strategies. The summary of descriptive statistics of tomato fruit rot incidence and severity are present in Table 1.

The tomato rot incidence ranged from 10.22$44.17 \%$ with mean value $25.45 \%$, whereas rot severity was recorded from $0.7 \mathrm{~mm}$ to $7.10 \mathrm{~mm}$ length with mean value of $3.14 \mathrm{~mm}$. The incidence and severity had 11.06 and 2.00 Std. Dev and 43.39 and 63.81 coefficient of variation. The semivariogram parameters of the spherical model applied to the tomato rot distribution is given in Table 2 .

Table 1. Descriptive statistics for tomato fruit rot incidence and severity.

\begin{tabular}{cccccccc}
\hline Parameters & Min & Max & Mean & Std. Dev. & Skewness & Kurtosis & C.V\% \\
\hline TRI & 10.22 & 44.17 & 25.45 & 11.06 & 0.216 & 1.74 & 43.49 \\
TRS & 0.70 & 7.10 & 3.14 & 2.00 & 0.50 & -0.98 & 63.81 \\
\hline
\end{tabular}

TRI \& S: Tomato rot incidence \& severity

Table 2. Semivariogram parameters of tomato rots incidence and severity.

\begin{tabular}{cccccccc}
\hline Parameters & Range & $\mathbf{N}\left(\mathbf{C}_{\mathbf{0}}\right)$ & PS $(\mathbf{C})$ & $\mathbf{S ~}\left(\mathbf{C}_{\mathbf{0}}+\mathbf{C}\right)$ & N/S ratio & SDI \% & Spatial dependence \\
\hline TRI & 103.76 & 0.390 & 0.410 & 0.80 & 0.487 & 48.74 & Moderate \\
TRS & 61.780 & 0.453 & 1.590 & 2.043 & 0.221 & 22.17 & Weak \\
\hline
\end{tabular}

TRI \& S: Tomato rot incidence and severity; N: nugget; PS: partial sill; Sill; N/S ratio = [N/ (N+PS)]
The ratio of nugget to sill variance designates the grade of spatial correlation with ratios $\leq 25 \%, 25-75 \%$, and $\geq 75 \%$ displays strong, moderate and weak spatial correlation respectively. In particular; rot incidence data had a nugget/ sill ratio of 0.487 inferring moderate spatial dependence. This means that $51.3 \%$ of the total variation in tomato rot incidence can be explained by spatial variation, while the remaining $48.7 \%$ was attributable to unexplained sources of variations. Tomato rot severity inferring strong spatial dependence with a nugget/ sill ratio of 0.221 . It indicates that $77.9 \%$ was spatial variation, semivariogram of tomato rot incidence and severity were shown in Fig. 4-5.

Geographical information system was used to produce maps that represent the spatial distribution of tomato rot incidence and severity. The geographical distributions of tomato rot incidence and severity map is depicted in Fig. 6 and 7, which shows high incidence with red color, while low incidence with green and light green shades.

The yellow color in the map indicates high severity, whereas brown and red shades depict low severity. Amongst the infected tomato fruits samples; nine post-harvest rotting fungi were isolated namely; Geotrichum candidum, Alternaria alternata, Aspergillus flavus, Aspergillus niger, Bipolaris Fusarium oxysporum, Rhizopus stolonifer, Culvularia lunata and Penicillum digitatum. Relative percentage of occurrence varies with location and species. Location wise higher occurrence percentage of fungi was recorded in $\mathrm{L}_{1}$ and $\mathrm{L}_{4}$, while least in $\mathrm{L}_{2}$. Species wise relative frequency percentage was ranging from $6.38-17.02 \%$. Highest mean frequency percentage was recorded for Aspergillus flavus (17.02\%) followed by Fusarium oxysporum (18.89\%) and Alternaria alternata $(12.76 \%)$. The least occurrence percentage $(6.38 \%)$ was recorded for Culvularia lunata (Table 3 and Fig. 8). whereas, $22.1 \%$ was due to other sources of variation. The 


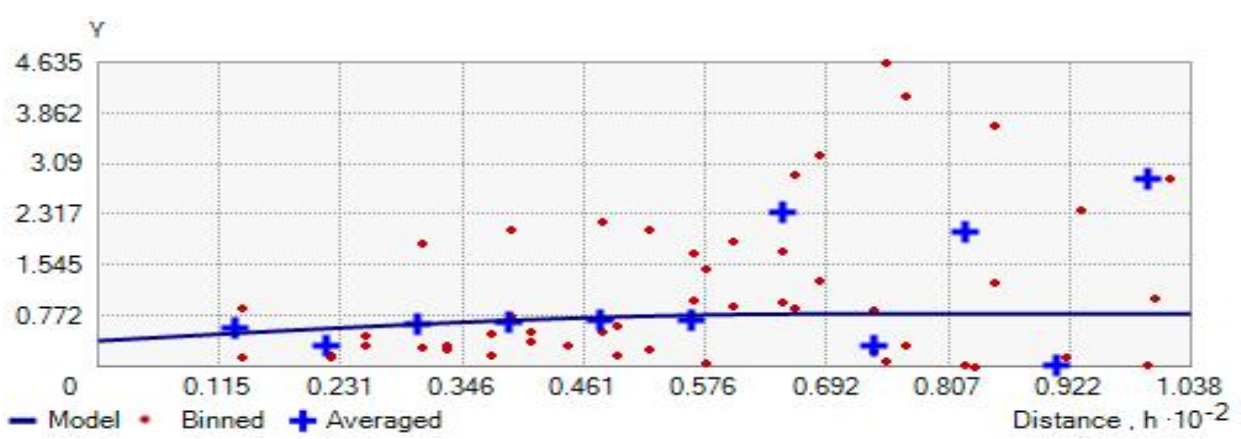

Figure 4. Semivariogram model to predict tomato fruit rot incidence of study area

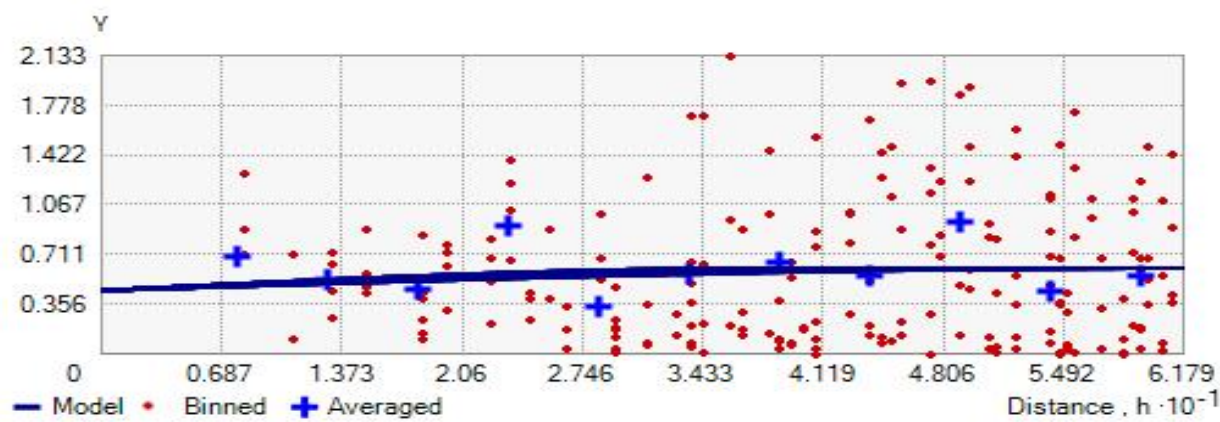

Figure 5. Semivariogram model to predict tomato fruit rot severity of study area

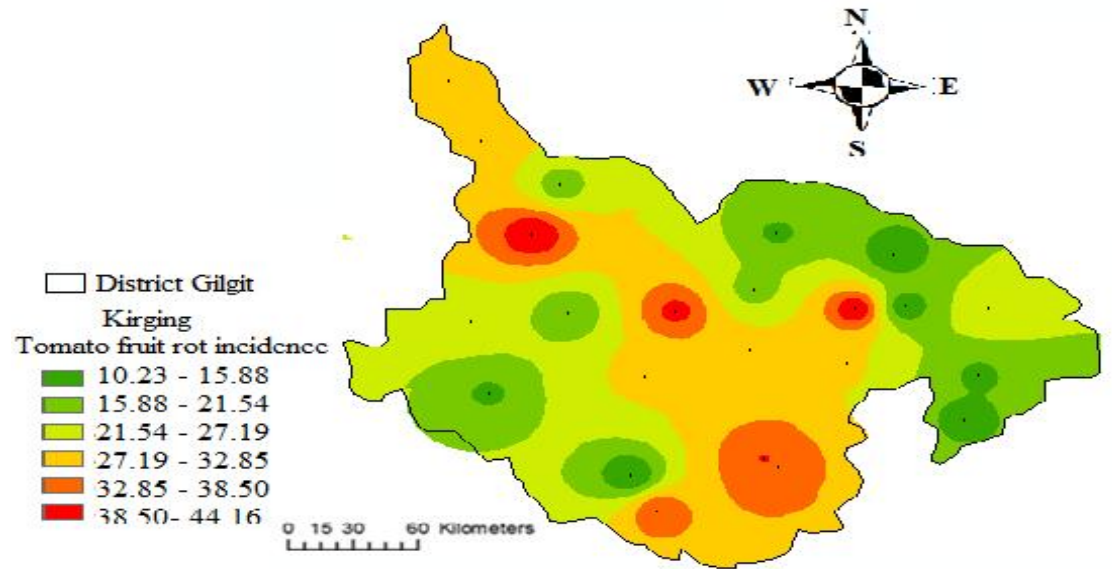

Figure 6. Spatial variability of tomato fruit rot incidence in District Gilgit

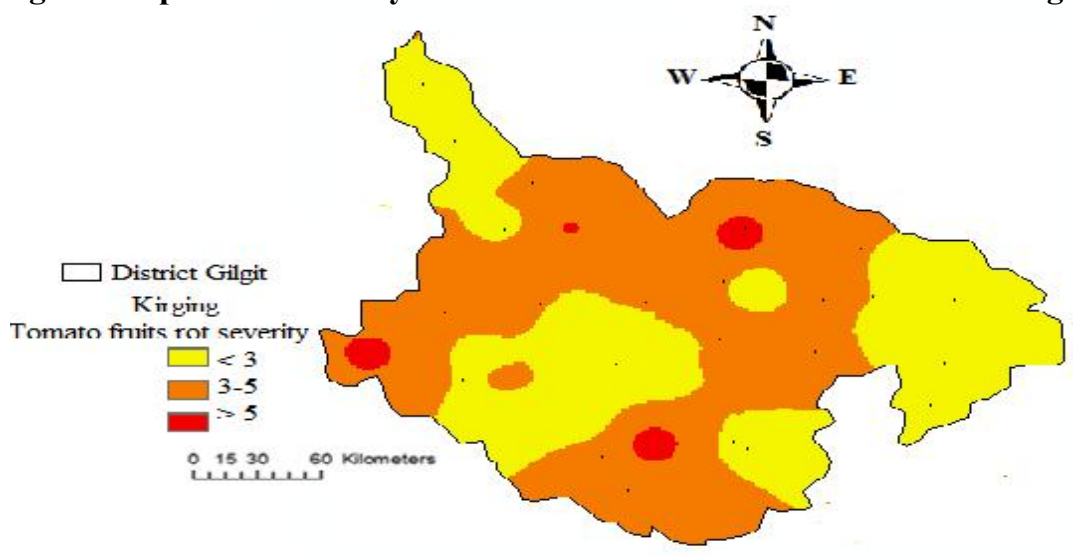

Figure 7. Spatial variability of tomato fruit rot severity in District Gilgit 
Table 3. Relative percentage occurrence and diversity index of tomato rot fungi at different location.

\begin{tabular}{lcccccc}
\hline & $\mathbf{L}_{\mathbf{1}}$ & $\mathbf{L}_{\mathbf{2}}$ & $\mathbf{L}_{\mathbf{3}}$ & $\mathbf{L}_{\mathbf{4}}$ & $\mathbf{L}_{\mathbf{5}}$ & Mean \% \\
\hline Geotrichum candidum & $3.0(75.0)$ & $0.0(0.0)$ & $0.0(0.0)$ & $1.0(25.0)$ & $0.0(0.0)$ & $4(8.51)$ \\
Alternaria alternata & $0.0(0.0)$ & $1.0(16.66)$ & $0.0(0.0)$ & $3.0(50.0)$ & $2.0(33.34)$ & $6(12.76)$ \\
Aspergillus flavus & $3.0(37.50)$ & $0.0(0.0)$ & $2.0(25.0)$ & $0.0(0.0)$ & $3.0(37.50)$ & $8(17.02)$ \\
Aspergillus niger & $0.0(0.0)$ & $3.0(60.0)$ & $2.0(40.0)$ & $0.0(0.0)$ & $0.0(0.0)$ & $5(10.63)$ \\
Bipolaris & $2.0(40.0)$ & $0.0(0.0)$ & $0.0(0.0)$ & $2.0(40.0)$ & $1.0(20.0)$ & $5(10.63)$ \\
Fusarium oxysporum & $3.0(42.86)$ & $0.0(0.0)$ & $2.0(28.57)$ & $2.0(28.57)$ & $0.0(0.0)$ & $7(14.89)$ \\
Rhizopus stolonifer & $2.0(40.0)$ & $0.0(0.0)$ & $0.0(0.0)$ & $2.0(40.0)$ & $1.0(20.0)$ & $5(10.63)$ \\
Culvularia lunata & $0.0(0.0)$ & $0.0(0.0)$ & $2.0(66.66)$ & $1.0(33.33)$ & $0.0(0.0)$ & $3(6.38)$ \\
Penicillum digitatum & $0.0(0.0)$ & $2.0(50.0)$ & $0.0(0.0)$ & $0.0(0.0)$ & $2.0(50.0)$ & $4(8.51)$ \\
Total & $13.0(28.26)$ & $5.0(10.86)$ & $8.0(17.39)$ & $11.0(23.91)$ & $9.0(19.56)$ & \\
Simpson's index & 0.86 & 0.60 & 0.85 & 0.89 & 0.86 & \\
Shannon-Wiener index & 1.55 & 1.58 & 1.36 & 1.69 & 1.50 & \\
\hline
\end{tabular}

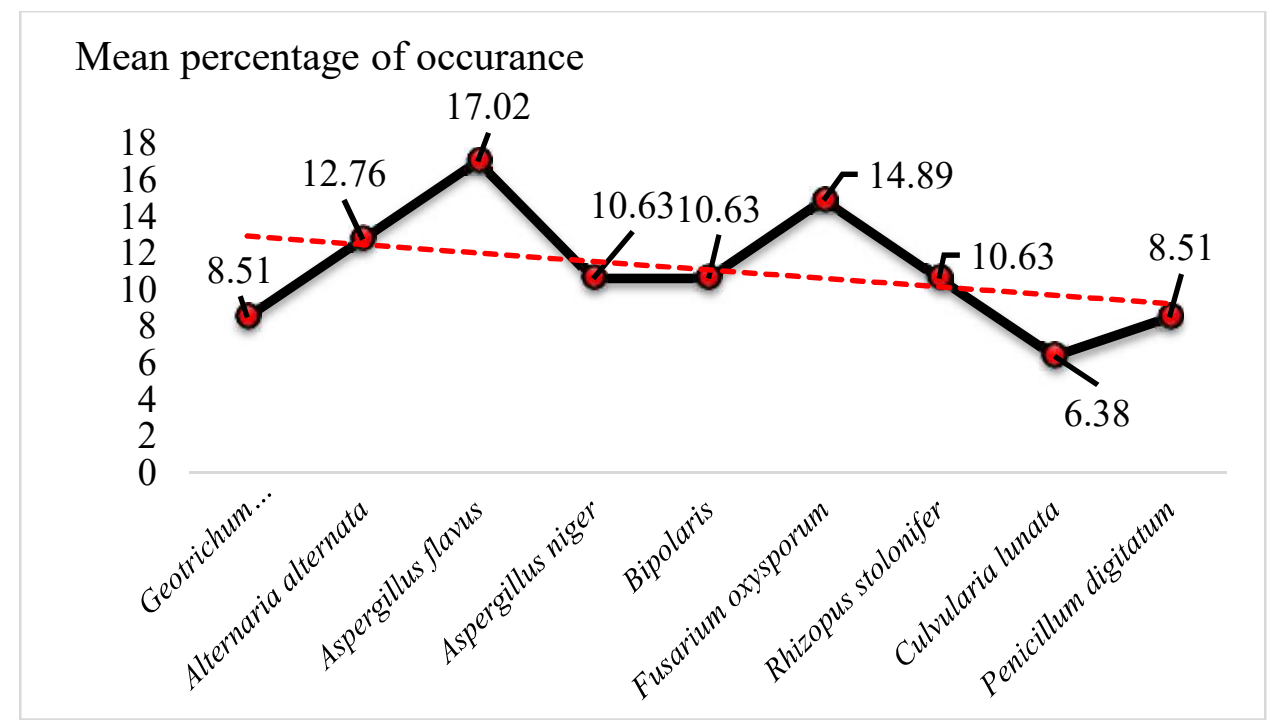

Figure 8. Mean percentage of tomato rot fungi.

\section{DISCUSSION}

Effective planning regarding crop protection requires accurate and reliable assessment of the disease; in addition to the identification of causal agent. The spatial pattern of disease distribution in the field has recently gained more attention. Thus, better understanding of the spatial distribution is key to effective mapping of disease severity, overall infestation level and optimization of control measures. In the current study, geostatistical methods were used to characterize spatial analysis of tomato rot in district Gilgit, Gilgit-Baltistan, Pakistan.

Spatial analysis of disease distribution can help us to identify the hot spot area which may lead to highlight risk factors to manage postharvest problems (Bivard et al., 2008). The results of current study indicate that tomato rot is spatially distributed in the study area. This was further confirmed by nugget/ sill ratio that tomato rot disease is spatially distributed in the area. Geostatistical techniques can be used to compute the degree, range and spatial dependence patterns of disease over the time (Rekah et al., 1999). Previously, several studies have been conducted by using geostatistical techniques to elaborate spatiotemporal development of plant disease (Van de Lande and Zadoks 1999; Jaime-Garcia et al., 2001). The interpolation maps specified that tomato rot incidence and severity was not uniformly distributed in the study area. These maps are useful in developing site specific disease management (Alizadeh et al., 2017) and highlight different agricultural issue (Deleon et al., 2017). Hence such technologies are playing key role to assist decision makers in establishing tactics for fighting against pests and diseases (Sabtu et al., 2018). The distribution of tomato rot in the study area was heterogeneous. The observed coefficient of variation (CV) of tomato rot incidence $(43.49 \%)$ and severity $(63.81 \%)$ representing heterogeneity of the data. According to Frogbrook et al. (2002) and Gomes and Garcia (2002); CV values $>10 \%$ can be considered the first indicator of heterogeneity of data or presence of diseased plants in different locations. 
In the current investigation; nine different fungal species were isolated from infected tomatoes which caused significant postharvest losses in the study area. It has been established that fruit rot of tomato is commonly triggered by different opportunistic fungal pathogens. These pathogens are widespread in the environment. Mechanical injuries during harvesting and handling provide room for infection and subsequent fruits decay by the pathogens. Fruit decay is activated with the change in physiological state of fruits, which may further enhance due to poor handling, storage and transportation practices (Wilson et al., 1991). Additional factors like low $\mathrm{pH}$, higher moisture level and nutrient composition make fruits very susceptible to pathogenic fungi. In addition to causing rots; these pathogens also produce mycotoxins (Moss, 2002). The results obtained from the current study indicated that nine fungi were associated with tomato fruits with different occurrence percentage. Similar rotting fungal species were also recovered from tomato fruit by Muhammad et al., (2004). These results agree with those of Chuku et al. (2010) who reported that Fusarium spp. R. stolonifer and Aspergillus spp. were responsible for soft rot of tomato. Ijato et al. (2011) isolated A. niger, $F$. oxysporum, $R$. stolonifer and $G$. candidium from rotten tomato fruits. F. moniliforme, A. niger and $R$. stolonifer were isolated from rotten tomato fruits (Chuku et al., 2008). The decay of fruits during storage is due to the micro-organisms which could have gained entry through cracks and surface injuries (Onuoral and Orji, 2015). According to Kader (2002), the pathogens infect fruits during prolonged periods of rainfall and high humidity, especially when fruits are poorly packed. The consequences of microbial contamination on tomato fruits causes spoilage, lessened sensory appeal and shelf life leading to loss and wastage of product that have significant economic cost. The microbiological safety of these products has also become a significant issue; as the incidence of food borne disease outbreaks are associated with their consumption (Obunukwu et al., 2018). Based on the information of current research work; It is suggested that intake of contaminated tomato's should be avoided. Mitigation measures must be employed by tomato growers, marketers and consumers at the time of harvesting, transportation, handling, storage and processing of tomato fruits.

Conclusion: This study discloses that tomato fruit rot is spatially distributed and massively infected with different fungal species. A total of nine fungal species were isolated from tomato fruits. Amongst; the highest occurrence percentage was in Aspergillus flavus followed by Fusarium oxysporum and Alternaria alternata. The high prevalence of tomato rot fungi necessitates appropriate management strategies. Adequate pre-post practices of produce would be fruitful to minimize wastes and enhance sustainable livelihood options. The current endeavor refers the effective role of GIS for highlighting as well as easily understanding of agriculture problems through thematic maps. Spatial distribution mapping and geostatistical analysis will be useful for researchers, extension worker and farmers in selection of cultivars and develop appropriate post-harvest practices for managing better crop and income.

Acknowledgments: The authors are grateful to Karakorum International University Gilgit, GilgitBaltistan for providing the financial assistance to carry out this research work.

\section{REFERENCES}

Agrios, G. N. (2005). Plant Pathology. 5th. New York: Elsevier.

Akinmusire, O.O. (2011). Fungal species associated with the spoilage of some edible fruits in Maiduguri, Northern Eastern Nigeria. Adv. Envi. Bio. 5(1): 157-161.

Ali, S., V.V. Rivera and G.A. Secor (2005). First report of Fusarium gramincearum causing dry rot of potato in North Dakota. Plant Dis. 89(1):105. doi: 10.1094/PD-89-0105B.

Alizadeh, M., M. Moharrami and A.A. Rasouli (2017). Geographic information system (gis) as a tool in the epidemiological assessment of wetwood Disease on elm trees in Tabriz city, Iran. Cercetari Agronomice în Moldova. 2(170): 91100.

Azhar, H., S. A. Muhammad, A. Sartaj, W.K Sher, M. Francesco and A. Shamsher (2016). Spatial variability of soil micronutrients $(\mathrm{Cu}, \mathrm{Fe}, \mathrm{Zn} \&$ $\mathrm{Mn}$ ) and population dynamic of mycoflora in potato fields of CKNP region Gilgit-Baltistan Pakistan. P.J.A.S. 53(3):541-550.

Baiyewu, R.A., N.A. Amusa, O.A. Ayoola and O.O. Babalola (2007). Survey of the post-harvest diseases and aflatoxin contamination of marketed pawpaw fruit (Carica papaya $\mathrm{L}$ ) in south western Nigeria. A.J.A.S. 2(4): 178-181.

Barth, M., T. R. Hankinson, H. Zhuang and F. Breidt (2009). Microbiological spoilage of fruits and vegetables in Compendium of the microbiological spoilage of foods and beverages, Springer, New York, NY, USA.

Biondi, F., D.E. Myers and C.C. Avery (1994). Geostatistical modeling stem size and increment in an old-growth forest. Can. J. For. Res. 24:1354-1368. doi:10.1139/x94-176.

Bivand, R. S., E.J. Pebesma and V. Gomez-Rubio (2008). Applied spatial data analysis with R. New York; London: Springer.

Caers, J. (2003). Geostatistics: from pattern recognition to pattern reproduction. In: Nikravesh $M$, 
Aminzadeh F, Zadeh L (eds) Soft computing and intelligent data analysis in oil exploration. Elsevier, Amsterdam, 51: 97-115.

Chuku, E. C., J. A. Osakwe and C. Daddy-West (2010). Fungal spoilage of tomato (Lycopersicon esculentum Mill) control using garlic and ginger. Sci. Africana. 9(2): 42-50.

Chuku, E.C., D.N. Ogbonna, B.A. Onuegbu and M.T.V. Adeleke (2008). Comparative Studies on the Fungi and Bio-Chemical Characteristics of Snake Gourd (Trichosanthes curcumerina Linn) and Tomato (Lycopersicon esculentus Mill) in Rivers State, Nigeria. J. Applied Sci. 8(1): 168-172.

Deleon, L, M.J. Brewer, I.L. Esquivel and J. Halcomb (2017). Use of a geographic information system to produce pest monitoring maps for south Texas cotton and sorghum land managers. Crop Prot.101:50-57.

Effiuvwevwere, B.J.O. (2000). Microbial spoilage agents of tropical and assorted fruits and vegetables (An illustrated Reference Book). Paragraphics publishing company, Port Harcourt, 1-39.

FAOSTAT. (2019). Available at: http://www.fao.org/ faostat/en/\#home [Accessed April 15, 2019].

FAO. (2005). Web site database. http://www.fao.org

Frogbrook, Z.L., M.A. Oliver, M. Salahi and R.H. Ellis (2002). Exploring the spatial relations between cereal yield and soil chemical properties and the implications for sampling. Soil Use and Magt, Medford. 18(1):1-9.

Ewulo, B.S., S.O. Ojeniyi and O.A. Akanni (2008). Effect of Poultry manure on selected soild physical and chemical properties on growth, yield and nutrient status of tomato. J. Agric. Res. 3(1): 613-616.

Gomes, F.P. and C.H. Garcia (2002). Statistics Applied to Agronomic Experiments and Forestry.] FEALQ, Piracicaba, 309.

Hyde, K.D., J.E. Taylor and J. Fröhlich (2000). Genera of Ascomycetes from Palm. Fungal Diversity Press, Hong Kong.

Ijato, J.Y. (2011). Inhibitory effect of two indigenous plant extracts of Zingiber officinale and Ocimum gratissimum on post-harvest yam (Dioscorea rotundata) rot in vitro. J. Ame. Sci. 7(1):43-47.

Iqbal, S.M., Z.A. Ghafoor and A.M. Haqqani (2003). Pathogenicity and fungicidal efficacy for sclerotinia rot of brinjal. I.J.A.B. 5(4):618-620. doi 560-8530/2003/05-4-618-620 http:// www.ijab.org.

Jaime-Garcia, R., T. V. Orum, R. Felix-Gastelum, R.Trinidad, H.D. CorreaVanEtten and M.R. Nelson (2001). Spatial analysis of Phytophthora infestans genotypes and late blight severity on tomato and potato in Del Fuerte Valley using geostatistics and geographical information systems. Phytopath. 91:1156-1165.
Kader, A.A. and R.S. Rolle (2002). In the role of postharvest management in assuring the quality and safety of horticultural produce, FAO Food and Agricultural Organizations of the United Nations, Rome.

Kader, A.A. (2005). Increasing food availability by reducing postharvest losses of fresh produce. Acta Hortic, 682, 2169-2176. DOI: 10.17660/ActaHortic.682.296.

Kalyoncu, F., A.U. Tamer, and M, Oskay, (2005). Determination of fungi associated with tomatoes (Lycopersicum esculentum M.) and tomato pastes. Plant Path. J, 4: 146-149.

Moss, M.O. (2002). Mycotoxin review. 1. Aspergillus and Penicillium. Mycologist. 16: 116-119.

Muhammad, S. K. Shehu and N.A. Amusa (2004). Survey of the market diseases and aflatoxin contamination of tomato (Lycopersicon esculentum MILL) fruits in Sokoto, northwestern Nigeria. Nutri \& Food Sci. 34(2):72-76.

Obunukwu., G.M. K.S. Dike, and G.E. Nwakwasi (2018). Isolation and identification of microbial deteriogens of fresh tomatoes stored at ambient temperature. M.R.J.I. 26(1): 1-8.

Olea, R.A. (2003). Geostatistics for engineers and earth scientists. Norwell: Kluwer Academic Publishers.

Onuorah, S. and M.U. Orji (2015). Fungi Associated with the Spoilage of Post-harvest Tomato Fruits Sold in Major Markets in Awka, Nigeria. Uni. J. Microbiology Res. 3(2): 11-16.

Patel, N.A., S.R.S. Dange and S.I. Patel (2005). Efficacy of chemicals in controlling fruit rot of tomato caused by Alternaria tomato. Indian J. Agric. Res. 39: 72-75.

Quinet, M., T. Angosto, F.J. Yuste-Lisbona, R. BlanchardGros, S. Bigot, J.P. Martinez and S. Lutt (2019): Tomato fruit development and metabolism. Front. Plant Sci. 10:1554. doi: 10.3389/fpls.2019.01554.

Rekah, Y., D. D. Shtienberg and J. Katan (1999): Spatial distribution and temporal development of Fusarium crown disease and root rot of tomato and pathogen dissemination in field soil. Phytopath. 89, 831-839.

Richard, S., G.E. Ostfeld and K. Felicia (2005). Spatial epidemiology: an emerging (or re-emerging) discipline. Trends Eco \&amp; Evol. 20(6): 328336.

Sabtu N. M., N.H. Idris and M.H.I. Ishak (2018).The role of geospatial in plant pests and diseases: an overview IOP Conference Series: Earth and Environmental Science. IOP Conf. Ser. Earth Environ. Sci. 169(1): 012013 https://doi.org/ 10.1088/1755-1315/169/1/012013. 
Singh, D. and R.R. Sharma (2007). Postharvest disease of fruit and vegetables and their management. In: Prasad, D. edition sustainable pest management. Daya Publishing House,

Van de Lande, H. L. and J. C. Zadoks (1999). Spatial patterns of spear rot in oil palm plantations in Surinam. Plant Pathol. 48: 189-201.

Wani, A.H, (2011). An overview of the fungal rot of tomato. Mycopath. 9(1): 33-38.

Wamache, A. (2005). Vegetable seeds handbook. Regina seeds Seminis. Printed by Bizone ltd.
Webster, R. and M.A. Oliver (2007). Geostatistics for environmental scientists. 2. Chichester: Wiley; 2007.

Wilson, C.L., M.E. Wisniewski, C.L. Biles, R. McLaughlin, E. Chalutz and S. Droby (1991). Biological control of post-harvest diseases of fruits and vegetables: alternative to synthetic fungicides. Crop Prot. 10: 172-177.

Zar, H. J. (2004). Biostatistical Analysis, fourth ed. Pearson Education Pvt. Ltd., Delhi, p. 663. 